\title{
Tipos e doses de adubação orgânica no crescimento, no rendimento e na composição química do óleo essencial de elixir paregórico
}

\author{
Sources and doses of organic fertilization in Ocimum selloi growth, essential oil yield and chemical \\ composition
}

\author{
Larissa Corrêa do Bomfim Costa ${ }^{\mathrm{I}}$ José Eduardo Brasil Pereira Pinto ${ }^{\mathrm{II}}$ Evaristo Mauro de Castro ${ }^{\mathrm{III}}$ \\ Suzan Kelly Vilela Bertolucci ${ }^{\text {II }}$ Ricardo Monteiro CorrêaII Érika Soares Reis ${ }^{\text {II }}$ \\ Péricles Barreto Alves $^{\text {IV }}$ Edenilson dos Santos Niculau ${ }^{\text {IV }}$
}

\section{RESUMO}

A prática da adubação orgânica, além de fornecer nutrientes para as plantas, proporciona a melhoria da estrutura física do solo, aumenta a retenção de água, diminui as perdas por erosão e favorece o controle biológico. O elixir paregórico (Ocimum selloi Benth.) é uma espécie medicinal nativa das regiões Sul e Sudeste do Brasil onde é utilizada popularmente como antidiarréico, antiespasmódico e antiinflamatório. Este trabalho teve como objetivo verificar o efeito de diferentes doses de dois adubos orgânicos no crescimento, no rendimento e na composição do óleo essencial de elixir paregórico. Os experimentos foram conduzidos em Lavras, MG, em estufa plástica com os seguintes tratamentos de adubação: ensaio A - esterco bovino: 1) sem adubação (controle); 2) solo $+3 \mathrm{~kg} \mathrm{~m}^{-2}$ de esterco; 3) solo $+6 \mathrm{~kg}$ $\mathrm{m}^{-2}$ de esterco; 4) solo $+9 \mathrm{~kg} \mathrm{~m}^{-2}$ de esterco; 5) solo $+12 \mathrm{~kg}$ $\mathrm{m}^{-2}$ de esterco; ensaio B - Esterco avícola: 1) sem adubação (controle); 2) solo $+1,5 \mathrm{~kg} \mathrm{~m}^{-2}$ de esterco; 3) solo $+3 \mathrm{~kg} \mathrm{~m}^{-2} \mathrm{de}$ esterco; 4) solo $+4,5 \mathrm{~kg} \mathrm{~m}^{-2}$ de esterco e 5) solo $+6 \mathrm{~kg} \mathrm{~m}^{-2}$ de esterco. Foi verificada a influência das doses de adubação com esterco bovino e galinha sobre o crescimento da planta em altura e diâmetro do caule, acúmulo de biomassa seca, AF, AFE, RPF, teor de clorofilas, espessura do limbo foliar, rendimento $e$ composição química do óleo essencial.

Palavras-chave: Ocimum selloi Benth., planta medicinal, adubação orgânica.

\section{ABSTRACT}

The organic fertilization provides nutrients for the plants, improves the soil physical structure, increases the water retention, reduces the erosion losses and favors the biological control. Ocimum selloi is a native medicinal plant of south and southeast of Brazil where is used popularly as antidiarrhetic, antispasmodic and anti-inflammatory. This research aimed to verify the effect of different doses of two organic fertilizers souces in $\mathbf{O}$. selloi growth, essential oil yield and chemical composition. The experiments were carried out in Lavras, MG, with pots in polyethylene greenhouse with two manuring treatments: Test A Cattle manure: 1) Soil without manuring (control); 2) Soil + $3 \mathrm{~kg} \mathrm{~m}^{-2}$ cattle manure; 3) Soil $+6 \mathrm{~kg} \mathrm{~m}^{-2}$ cattle manure; 4) Soil $+9 \mathrm{~kg} \mathrm{~m}^{-2}$ cattle manure; 5) Soil $+12 \mathrm{~kg} \mathrm{~m}^{-2}$ cattle manure; Test B - Chicken manure: 1) Soil without manuring (control); 2) Soil $+1.5 \mathrm{~kg} \mathrm{~m}^{-2}$ chicken manure; 3) Soil $+3 \mathrm{~kg} \mathrm{~m}^{-2}$ chicken manure; 4) Soil $+4.5 \mathrm{~kg} \mathrm{~m}^{-2}$ chicken manure and 5) Soil $+6 \mathrm{~kg}$ $\mathrm{m}^{-2}$ chicken manure. The influence of cattle and chicken manuring doses was verified on plant height, stem diameter, dry biomass weight, TLA, SLA, LWR, chlorophylls content, leaf thickness, essential oil yield and composition.

Key words: Ocimum selloi Benth., medicinal plant, organic fertilizer.

\section{INTRODUÇÃO}

A Ocimum selloi Benth. (Lamiaceae), conhecida vulgarmente como elixir paregórico, alfavaquinha ou atroveran, é uma espécie medicinal nativa das regiões Sul e Sudeste do Brasil Ela é encontrada em estado silvestre ou cultivada em hortas e quintais e é usada popularmente como antidiarréico, antiespasmódico e antiinflamatório.

A síntese de princípios ativos nas plantas medicinais é derivada do metabolismo secundário e

\footnotetext{
'Departamento de Ciências Biológicas (DCB), Universidade Estadual de Santa Cruz (UESC), Ilhéus, BA, Brasil. E-mail: larissacbc@uol.com.br.

IIDepartamento de Agricultura (DAG), Universidade Federal de Lavras (UFLA), Lavras, MG, Brasil.

IIIDepartamento de Biologia (DBI), UFLA, Lavras, MG, Brasil. E-mail: jeduardo@ufla.br. Autor para correspondência.

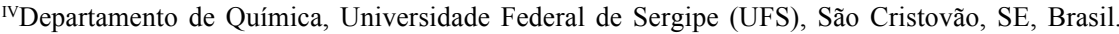


pode ser regulada tanto por fatores genéticos quanto ambientais. Entre os fatores de estresse que interferem na composição química da planta, a nutrição merece destaque, pois a deficiência ou o excesso de nutrientes pode interferir na produção de biomassa e na quantidade de princípio ativo (MAPELI et al., 2005). A adubação orgânica das plantas medicinais, além de ser parte essencial nos sistemas de cultivo orgânico, fornece nutrientes para as plantas, proporciona benefícios na estrutura física do solo, aumenta a retenção de água, diminui as perdas por erosão e favorece o controle biológico de pragas e doenças.

Nesse sentido, estudos sobre o rendimento de biomassa e óleo essencial em resposta à adubação orgânica, mineral e mista vêm sendo desenvolvidos com espécies medicinais como Justicia pectoralis (BEZERRA et al., 2006), Hyptis suaveolens (MAIA, 2006), Ocimum basilicum (BLANK et al., 2005), Chamomilla recutita (CORRÊA JÚNIOR, 1998; MAPELI et al., 2005), Lippia alba (MING, 1998) e Achillea millefolium (SCHEFFER, 1998).

O presente trabalho teve como objetivo verificar o efeito de diferentes doses de adubos orgânicos no crescimento vegetativo, no teor e na composição química do óleo essencial de elixir paregórico.

\section{MATERIAL E MÉTODOS}

O experimento foi instalado em estufa plástica de 18,5 x 13m, posição norte-sul, do Laboratório de Cultura de Tecidos Vegetais e Plantas Medicinais da Universidade Federal de Lavras (UFLA). Plantas obtidas a partir de sementes foram cultivadas em vasos de 10 litros com solo misturado aos seguintes tratamentos de doses de adubação orgânica: ensaio A - esterco bovino: 1) sem adubação (controle); 2) solo $+3 \mathrm{~kg} \mathrm{~m}^{-2}$ de esterco; 3 ) solo $+6 \mathrm{~kg} \mathrm{~m}^{-2}$ de esterco; 4) solo $+9 \mathrm{~kg} \mathrm{~m}^{-2}$ de esterco; 5) solo $+12 \mathrm{~kg} \mathrm{~m}^{-2}$ de esterco; enaio B - esterco avícola: 1) sem adubação (controle); 2) solo $+1,5 \mathrm{~kg} \mathrm{~m}^{-2}$ de esterco; 3 ) solo $+3 \mathrm{~kg} \mathrm{~m}^{-2} \mathrm{de}$ esterco; 4) solo $+4,5 \mathrm{~kg} \mathrm{~m}^{-2}$ de esterco e 5) solo $+6 \mathrm{~kg}^{-2}$ $\mathrm{m}^{-2}$ de esterco.

As características químicas do solo e dos adubos orgânicos foram determinadas seguindo análise de rotina em que foram obtidos os seguintes resultados para o solo: $\mathrm{pH}$ em água $=7,3 ; \mathrm{P} \mathrm{e} \mathrm{K}\left(\mathrm{mg} \mathrm{dm}^{-3}\right)=1,7$ e 9; $\mathrm{Ca}^{2+}, \mathrm{Mg}^{2+}, \mathrm{Al}^{3+}, \mathrm{H}+\mathrm{Al}\left(\mathrm{cmol}_{\mathrm{c}} \mathrm{dm}^{-3}\right)=5,7 ; 0,7 ; 0,0 ; 1,2$; índice de saturação de bases $(\%)=84,3$; matéria orgânica $($ dag kg-1 $)=3,0 ; \mathrm{Zn}, \mathrm{Fe}, \mathrm{Mn}, \mathrm{Cu}, \mathrm{B}$ e S (mg $\left.\mathrm{dm}^{-3}\right)=1,5 ; 31,1 ; 13,8 ; 1,1 ; 0,1$ e 14,9, respectivamente. Os adubos orgânicos, por sua vez, também foram analisados gerando os seguintes valores para o esterco bovino: $\mathrm{pH}$ em água $=8,2 ; \mathrm{P}, \mathrm{K}\left(\mathrm{mg} \mathrm{dm}^{-3}\right)=619,0 ; 8033$; $\mathrm{Ca}^{2+}, \mathrm{Mg}^{2+}, \mathrm{Al}^{3+}$ e $\mathrm{H}+\mathrm{Al}\left(\mathrm{cmol}_{\mathrm{c}} \mathrm{dm}^{-3}\right)=6,9 ; 3,6 ; 0,0 \mathrm{e}$ 0,89; SB e CTC $\left(\mathrm{cmol} \mathrm{dm}^{-3}\right)=31,0 ; 31,9 ; \mathrm{V}(\%)=97,2$, respectivamente. Para o esterco avícola: $\mathrm{pH}$ em água $=$ 8,2; P, K $\left(\mathrm{mg} \cdot \mathrm{dm}^{-3}\right)=1080,5 ; 8563 ; \mathrm{Ca}^{2+}, \mathrm{Mg}^{2+}, \mathrm{Al}^{3+} \mathrm{e}$ $\mathrm{H}+\mathrm{Al}\left(\mathrm{cmol}_{\mathrm{c}} \mathrm{dm}^{-3}\right)=2,4 ; 1,1 ; 0,0$ e 0,$77 ; \mathrm{SB}$ e CTC $\left(\mathrm{cmol}_{\mathrm{c}}\right.$ $\left.\mathrm{dm}^{-3}\right)=25,4 ; 26,2 ; \mathrm{V}(\%)=97,1$, respectivamente.

Após 80 dias de cultivo, foram ralizadas análises biométricas: altura das plantas (ALT) desde a superfície do solo até a extremidade da inflorescência presente no ápice do eixo principal e o diâmetro do caule na altura do coleto (COL). Aárea foliar total (AFT) foi medida utilizando-se um Medidor Eletrônico de Área Foliar, Modelo LI - 3100-LICOR, a partir da qual foram obtidos os parâmetros fisiológicos de razão de área foliar (RAF), área foliar específica (AFE) e razão de peso foliar (RPF), de acordo com BENINCASA (2003).

Em seguida, cada planta colhida foi particionada em raiz, caule, folha e inflorescência para secagem até peso constante para obtenção da biomassa seca, com a qual também foi determinada a relação raiz:parte aérea (R:PA).

Na mesma ocasião, foi colhida uma folha completamente expandida do segundo nó abaixo da inflorescência dos ramos centrais de cinco plantas diferentes, fixadas em FAA (Formol - Ácido acético Álcool) e estocadas em solução de etanol a 70\%. Foram preparadas lâminas semipermanentes da região mediana do limbo foliar, a partir de seções transversais à mão livre. Os cortes obtidos foram submetidos à coloração com safrablau 5\%. As medições dos componentes foliares (epidermes da superfície adaxial e abaxial e parênquimas paliçádico e lacunoso) foram feitas a partir de imagens digitais, utilizando-se o programa de análise de imagens Sigma Scan Pro 5.

Com um espectrofotômetro v/uv Beckman modelo 640 B foi realizada a leitura da absorbância dos extratos foliares a 663 e $645 \mathrm{~nm}$ para a quantificação das clorofilas $a, b$ e total, seguindo a metodologia de ARNON (1949).

O óleo essencial das folhas foi extraído pelo processo de hidrodestilação em aparelho de Clevenger, sendo utilizados $40 \mathrm{~g}$ de biomassa seca, em $500 \mathrm{~mL}$ de água destilada por 90 minutos. O teor e o rendimento de óleo essencial foram avaliados na biomassa seca 
das folhas (BSF). O teor de óleo foi obtido diretamente como porcentagem $\left(\mathrm{g} 100 \mathrm{~g}^{-1} \mathrm{BSF}\right)$ e o rendimento de óleo foi calculado por meio do teor multiplicado pelo valor médio de BSF da planta $\left(\mathrm{g}_{\mathrm{planta}} \mathrm{pl}^{-1}\right)$.

As amostras de óleo essencial foram analisadas por cromatografia gasosa (CG) utilizando aparelho Shimadzu 17 A equipado com detector de ionização de chama (FID) e também por cromatografia gasosa acoplada à espectrometria de massa (CG-EM), usando aparelho Shimadzu QP5050A. As condições cromatográficas em ambas as análises foram coluna capilar de sílica fundida com fase estacionária DB-5MS ( $30 \mathrm{~m} \times 0,2 \mathrm{~mm} \times 0,25 \mu \mathrm{m}$ de espessura de filme); He nas análises por CG-EM como gás de arraste com fluxo de $1,2 \mathrm{~mL} \mathrm{~min}^{-1}$, a temperatura foi programada mantendo $50^{\circ} \mathrm{C}$ por $1,5 \mathrm{~min}$, aumentando para $200^{\circ} \mathrm{C} \mathrm{a} 4^{\circ} \mathrm{C} \mathrm{min}^{-1}$, então aquecendo para $300^{\circ} \mathrm{C} \mathrm{a} 10^{\circ} \mathrm{C} \mathrm{min}^{-1}$ e mantendo esta temperatura constante por $10 \mathrm{~min}$; as temperaturas do injetor e do detector foram $250^{\circ} \mathrm{C}$ e $280^{\circ} \mathrm{C}$, respectivamente; o volume de injeção foi $0,2 \mu \mathrm{L}$ solução em acetato de etila com velocidade de arraste de $1,5 \mathrm{~mL}$ $\min ^{-1}$. As condições do EM foram detector de captura iônica operando por impacto eletrônico e energia de impacto de $70 \mathrm{e}-\mathrm{V}$. A velocidade de varredura foi de 0,5 scan $\mathrm{seg}^{-1}$ de 40 a $550 \mathrm{~m} \mathrm{z}^{-1}$. Cada componente foi identificado pela comparação dos espectros de massas obtidos com os dados da espectroteca on-line NIST 69 e dados da literartura (ADAMS, 1995). Os índices de retenção de Kovats (IK) foram determinados utilizando uma curva de calibração de uma série de $n$-alcanos $\left(\mathrm{C}_{8}\right.$ $\mathrm{C}_{18}$ ) injetados nas mesmas condições cromatográficas das amostras. Os valores de retenção obtidos foram confrontados com dados da literatura (VAN DEN DOOL \& KRATZ, 1963). A concentração dos constituintes foi calculada por meioda área integral de seus respectivos picos relacionada com a área total de todos os constituintes da amostra, obtida pela análise utilizando cromatógrafo a gás com detector de ionização de chamas (FID).

O delineamento experimental adotado foi em blocos casualizados com quatro repetições e quatro plantas por parcela. Os dados obtidos foram submetidos à análise de variância e à comparação de médias por meio do teste de Tukey a 5\% de probabilidade.

\section{RESULTADOS E DISCUSSÃO}

Nos dois ensaios, as plantas não-adubadas estavam visivelmente amareladas, com folhas menores e porte reduzido em relação às demais. Verificou-se que houve efeito significativo das doses de adubação do esterco bovino e do esterco avícola em todas as variáveis analisadas, seguindo uma tendência quadrática, com exceção do teor de clorofila total, cujo ajuste foi linear para o esterco avícola (Figuras 1, 2 e 3).

Foi observado aumento na altura das plantas com o incremento das doses de adubação, atingindo um valor máximo de $67,3 \mathrm{~cm}$ com a aplicação de $8 \mathrm{~kg} \mathrm{~m}^{-2}$ de esterco bovino e $78,0 \mathrm{~cm}$ com a dose de $4,7 \mathrm{~kg} \mathrm{~m}^{-2}$ de esterco avícola (Figura $1 \mathrm{~A} \mathrm{e} \mathrm{B}$ ). Estudos anteriores com Ocimum basilicum (BLANK et al., 2005) e Chamomilla recutita (CORRÊA JÚNIOR, 1998) não detectaram efeito das adubações orgânica e química sobre a altura das plantas medicinais, provavelmente por não terem avaliado o efeito de diferentes doses. $\mathrm{O}$ diâmetro do caule, que está relacionado à capacidade de transporte da planta, aumentou com as doses de adubação aplicadas, atingindo 11,1 e 13,7mm com a aplicação de $7,7 \mathrm{~kg} \mathrm{~m}^{-2}$ de esterco bovino e $4,8 \mathrm{~kg} \mathrm{~m}^{-2} \mathrm{de}$ esterco avícola, respectivamente (Figura $1 \mathrm{C}$ e D). Resposta semelhante do efeito de doses de adubação orgânica sobre o diâmetro do caule também foi encontrada para Hyptis suaveolens (MAIA, 2006).

Maior produção de biomassa seca total da planta $(66,3 \mathrm{~g})$ foi obtida com a dosagem de $9,7 \mathrm{~kg} \mathrm{~m}^{-2} \mathrm{de}$ esterco bovino e $101,3 \mathrm{~g}$ com a dose de $4,3 \mathrm{~kg} \mathrm{~m}^{-2}$ de esterco avícola. Nos dois tipos de adubação, a ordem de distribuição dos fotoassimilados seguiu a mesma seqüência: maior no caule, seguido de folhas, raiz e inflorescências (Figura $1 \mathrm{E} \mathrm{e} \mathrm{F).} \mathrm{O} \mathrm{efeito} \mathrm{das} \mathrm{doses} \mathrm{de}$ matéria orgânica no aumento de produção de biomassa já foi registrado para Hyptis suaveolens (MAIA, 2006) atribuindo-se à crescente disponibilidade e à absorção de nutrientes. Entretanto, este comportamento não é constante, pois em Justicia pectoralis as doses de adubações orgânicas e minerais não influenciaram a produção de biomassa da planta (BEZERRA et al., 2006). Quanto à relação R:PA, nas dosagens estudadas, os maiores valores foram obtidos no tratamento sem adubação, verificando-se diminuição da relação R:PA com o aumento das doses de adubo orgânico, até o valor de $0,23 \mathrm{com} 7,8 \mathrm{~kg} \mathrm{~m}^{-2}$ de esterco bovino e 0,20 com $4,1 \mathrm{~kg} \mathrm{~m}^{-2}$ de esterco avícola (Figura $1 \mathrm{G} \mathrm{e} \mathrm{H}$ ). Este resultado informa que o aumento das doses de adubo orgânico direciona a distribuição de biomassa para a parte aérea da planta. 


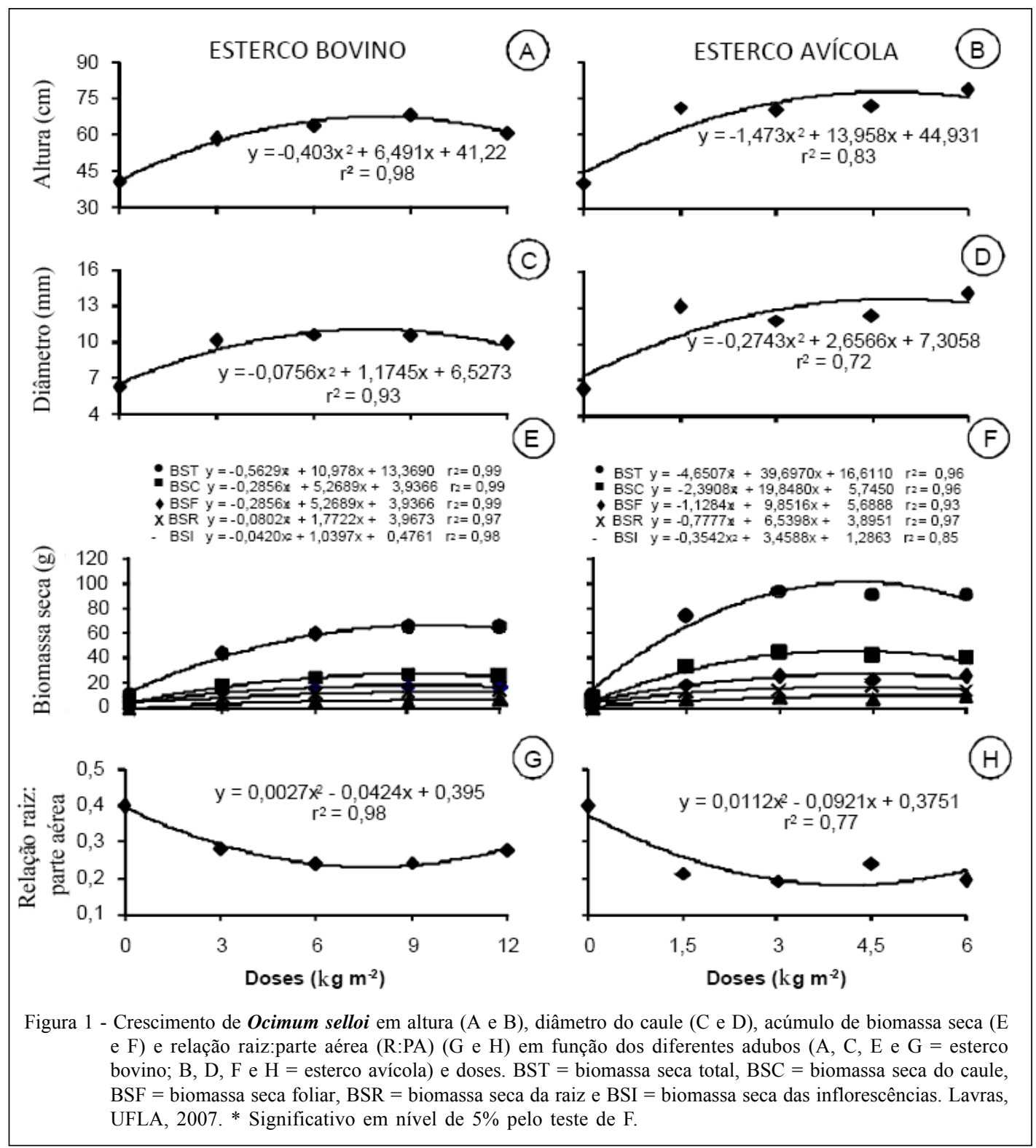

Com relação aos índices fisiológicos de crescimento, foi observado incremento da área foliar (AF) com as doses de adubação, atingindo os valores máximos de 4726,7 e $6084 \mathrm{~cm}^{2}$ com as doses de $9,6 \mathrm{~kg} \mathrm{~m}^{-2}$ de esterco bovino e $4,6 \mathrm{~kg} \mathrm{~m}^{-2}$ de esterco avícola, respectivamente (Figura $2 \mathrm{~A}$ e B). À semelhança do verificado com $\mathrm{AF}$, o incremento das doses dos adubos promoveu o aumento da área foliar específica (AFE), atingindo o valor máximo de $267,2 \mathrm{~cm}^{2} \mathrm{~g}^{-1}$ nas plantas adubadas com $9,0 \mathrm{~kg} \mathrm{~m}^{-2}$ de esterco bovino e $258,4 \mathrm{~cm}^{-2}$ $\mathrm{g}^{-1}$ com $5,8 \mathrm{~kg} \mathrm{~m}^{-2}$ de esterco avícola (Figura $2 \mathrm{C} \mathrm{e} \mathrm{D).} \mathrm{O}$ aumento da área foliar específica com doses crescentes de adubação orgânica está associado ao componente anatômico, ou seja, à redução significativa da espessura foliar. Não houve diferença significativa da razão de área foliar (RAF) em relação às doses de adubos (dados não apresentados), ou seja, a área foliar útil para a fotossíntese é a mesma. Apesar de as plantas adubadas produzirem maior área foliar e biomassa seca total do que as não-adubadas, há um aumento da interferência das folhas superiores sobre as folhas inferiores, causando um auto-sombreamento. Quanto à razão de peso foliar (RPF), nas dosagens estudadas, os maiores valores foram obtidos no tratamento sem 


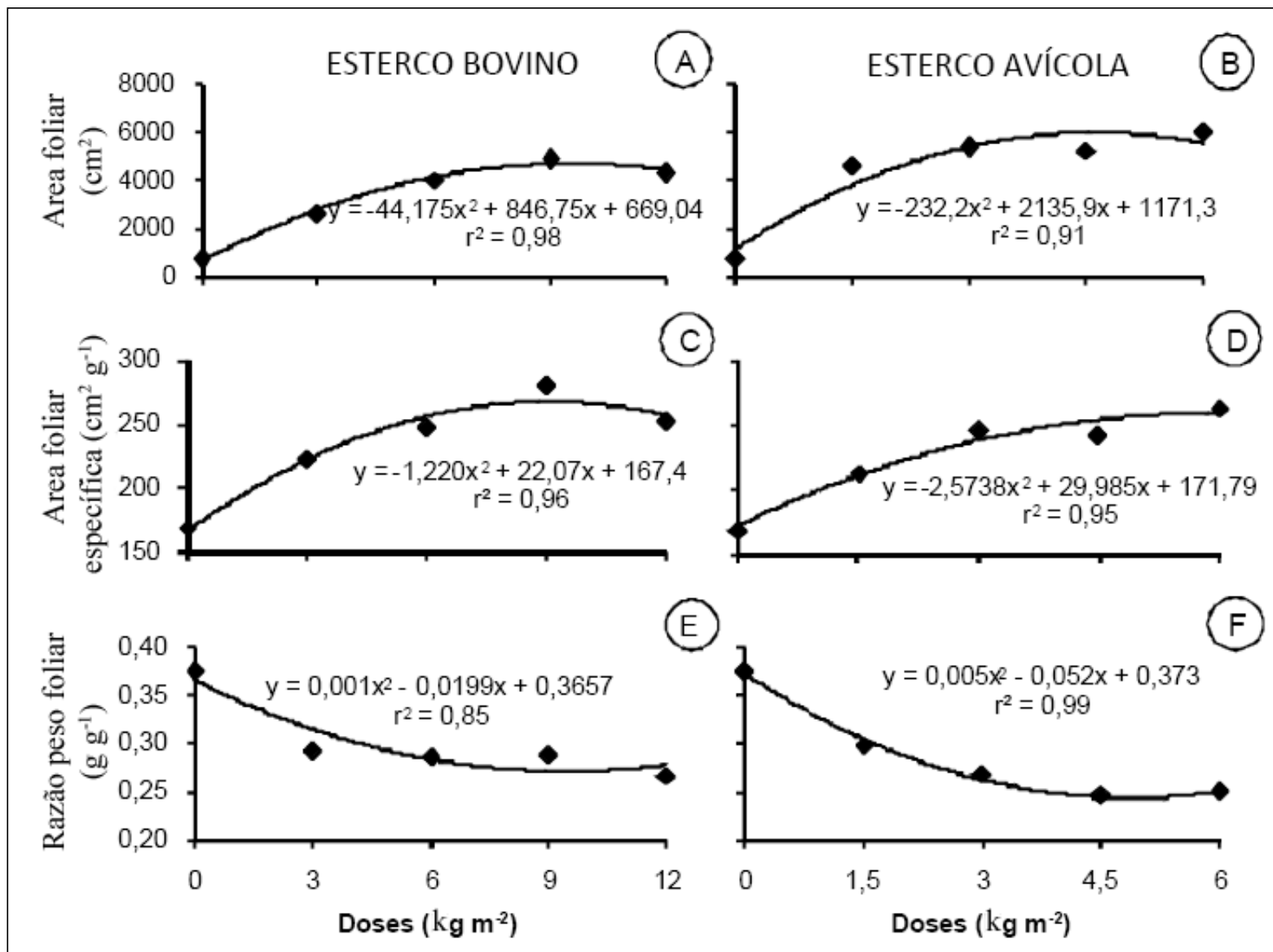

Figura 2 - Área foliar (AF) (A e B), área foliar específica (AFE) (C e D) e razão de peso foliar (RPF) (E e F) de Ocimum selloi em função dos diferentes adubos (A, C e E = esterco bovino; B, D e F = esterco avícola) e doses. Lavras, UFLA, 2007. * Significativo em nível de 5\% pelo teste de F.

adubação e à medida que as doses de adubo foram aumentadas os valores diminuíram até $0,27 \mathrm{~g} \mathrm{~g}^{-1} \mathrm{com}$ $9,9 \mathrm{~kg} \mathrm{~m}^{-2}$ de esterco bovino e $0,24 \mathrm{~g} \mathrm{~g}^{-1}$ com $4,9 \mathrm{~kg} \mathrm{~m}^{-2} \mathrm{de}$ esterco avícola (Figura 2 E e F), ou seja, menor é a fração de material retido nas folhas e maior é a exportação para as outras partes da planta como as inflorescências, por exemplo.

A espessura do limbo foliar decresceu com as doses de adubo aplicadas até o valor mínimo de $185,0 \mu \mathrm{m}$ com $11,1 \mathrm{~kg} \mathrm{~m}^{-2}$ de esterco bovino e $169,7 \mu \mathrm{m}$ com $5,8 \mathrm{~kg} \mathrm{~m}^{-2}$ de esterco avícola (Figura $3 \mathrm{~A} \mathrm{e} \mathrm{B).} \mathrm{A}$ diminuição da espessura associada ao aumento da área foliar com as doses de adubo orgânico revela um ajuste da planta na área responsável pela interceptação da energia luminosa e $\mathrm{CO}_{2}$, aumentando assim a sua eficiência fotossintética em condições nutricionais favoráveis.

Os teores de clorofila a, b e total aumentaram linearmente com as doses de esterco avícola enquanto que com o esterco bovino o ajuste quadrático das curvas apresentou um pico de $1,57 \mathrm{mg} \mathrm{g}^{-1}$ de clorofila total com a dose de $9,3 \mathrm{~kg} \mathrm{~m}^{-2}$ de adubo (Figura $3 \mathrm{C} \mathrm{e} \mathrm{D).}$ As plantas sem adubação estavamvisivelmente amareladas em relação às demais. Estas respostas estão ligadas diretamente ao aumento da disponibilidade nutricional, especialmente de $\mathrm{N}$ e $\mathrm{Mg}$, principais constituintes do anel porfirínico na molécula de clorofila.

O rendimento de óleo essencial extraído da biomassa seca foliar aumentou com as doses de adubo, atingindo o valor máximo de $0,23 \mathrm{~g}_{\text {planta }}{ }^{-1} \operatorname{com} 8,1 \mathrm{~kg}$ $\mathrm{m}^{-2}$ de esterco bovino e $0,31 \mathrm{~g} \mathrm{planta}^{-1}$ com $4,0 \mathrm{~kg} \mathrm{~m}^{-2} \mathrm{de}$ esterco avícola (Figura $3 \mathrm{E} \mathrm{e} \mathrm{F}$ ), confirmando que pode haver incremento no rendimento de óleo essencial por planta com o aumento dos níveis de nutrientes disponíveis no solo (SILVA et al., 2006). Entretanto, esta resposta pode variar com a espécie, pois em 


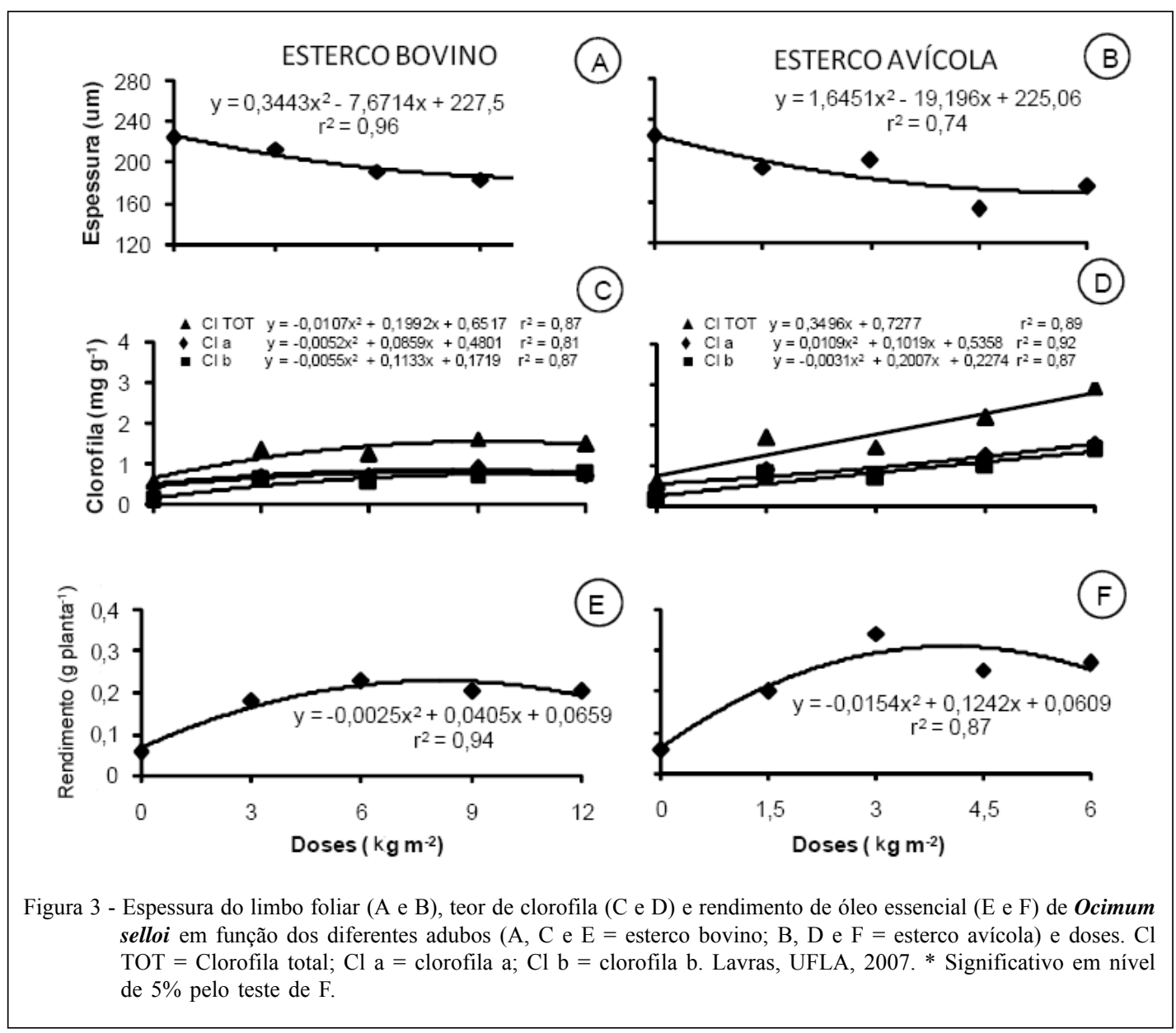

Achillea millefolium não houve alteração do rendimento de óleo essencial com as doses de adubo orgânico, apenas entre os tratamentos adubados e sem adubação (SCHEFFER, 1998).

A análise química do óleo essencial resultou na identificação de 19 compostos (Tabela 1). O óleo essencial de $\boldsymbol{O}$. selloi é constituído de fenilpropanóides e sesquiterpenos, sendo que o metil chavicol foi o seu constituinte majoritário, conforme já descrito anteriormente (MARTINS et al., 1997). Houve um incremento de aproximadamente $12 \%$ na biossíntese desse fitoconstituinte, independente do tipo e da dose de adubação orgânica em relação ao controle, ao contrário dos resultados obtidos em Baccharis trimera (SILVA et al., 2006). De modo geral, foram observadas diferenças quantitativas e qualitativas em termos de constituintes químicos do óleo essencial de $\boldsymbol{O}$. selloi, mas o maior número de compostos foi verificado no tratamento sem adubação, possivelmente como uma resposta de defesa da planta ao estresse nutricional.

\section{CONCLUSÕES}

Houve influência positiva das doses de adubação com esterco bovino e galinha sobre o crescimento da planta em altura e diâmetro do caule, acúmulo de biomassa seca, AF, AFE, RPF, teor de clorofilas, espessura do limbo foliar, rendimento e composição química do óleo essencial de $\boldsymbol{O}$. selloi, sendo que os maiores valores foram obtidos com a utilização de esterco bovino nas doses entre 8 e $10 \mathrm{~kg}$ $\mathrm{m}^{-2}$ e esterco avícola nas doses entre 4 e $5 \mathrm{~kg} \mathrm{~m}^{-2}$.

\section{AGRADECIMENTOS}

Ao Conselho Nacional de Desenvolvimento Científico e Tecnológico (CNPq), à Coordenação de Aperfeiçoamento de Pessoal de Nível Superior (CAPES) e

Ciência Rural, v.38, n.8, nov, 2008. 
Tabela 1 - Composição química e porcentagem da área do pico dos componentes do óleo essencial da biomassa seca de folhas de Ocimum selloi em função dos diferentes adubos e doses. Lavras, UFLA, 2007.

\begin{tabular}{|c|c|c|c|c|c|c|c|c|c|c|}
\hline \multirow[t]{2}{*}{ Constituinte } & \multirow[t]{2}{*}{$\mathrm{IR}^{*}$} & \multicolumn{5}{|c|}{-----------Doses esterco bovino $\left(\mathrm{kg} \mathrm{m}^{-2}\right)$----------- } & \multicolumn{4}{|c|}{-------Doses esterco avícola $\left(\mathrm{kg} \mathrm{m}^{-2}\right)$------ } \\
\hline & & 0 & 3 & 6 & 9 & 12 & 1,5 & 3 & 4,5 & 6 \\
\hline Metil-chavicol & 1195 & 81,73 & 90,02 & 91,96 & 92,34 & 91,66 & 91,36 & 92,38 & 92,68 & 90,43 \\
\hline Chavicol & 1253 & - & - & - & - & - & - & - & & 0,05 \\
\hline$\alpha$-Copaeno & 1376 & 0,20 & 0,20 & 0,18 & 0,16 & 0,18 & 0,19 & 0,19 & 0,16 & 0,23 \\
\hline$\beta$-Bourboreno & 1384 & 0,06 & - & - & - & - & - & - & - & - \\
\hline$\beta$-Cubebeno & 1390 & 0,05 & - & - & - & - & - & - & - & - \\
\hline$\beta$-Elemeno & 1391 & 0,09 & - & - & - & - & - & - & - & 0,11 \\
\hline Metil eugenol & 1401 & 1,38 & 0,79 & 0,62 & 0,56 & 0,63 & 0,66 & 0,60 & 0,56 & 0,79 \\
\hline$\beta$-Cariofileno & 1418 & 2,61 & 1,75 & 1,54 & 1,59 & 1,63 & 1,61 & 1,45 & 1,46 & 1,76 \\
\hline$\alpha$-trans-Bergamoteno & 1436 & 0,41 & 0,26 & 0,21 & 0,21 & 0,22 & 0,21 & 0,19 & 0,18 & 0,26 \\
\hline Acetato $(E)$-cinamil & 1443 & 0,03 & - & - & - & - & - & - & - & - \\
\hline$\alpha$-Cariofileno & 1454 & 2,24 & 0,08 & - & - & - & 1,61 & 1,45 & 1,46 & 1,76 \\
\hline Alo-Aromadendreno & 1461 & 0,12 & 0,05 & - & - & - & - & - & - & - \\
\hline Germacreno D & 1480 & 3,91 & 2,49 & 2,05 & 1,99 & 2,22 & 2,34 & 1,95 & 1,93 & 2,39 \\
\hline Biciclogermacreno & 1494 & 5,14 & 2,87 & - & - & - & - & - & - & 2,66 \\
\hline Germacreno A & 1503 & - & - & 2,41 & 2,29 & 2,56 & 2,70 & 2,21 & 2,24 & - \\
\hline$\beta$-Bisaboleno & 1509 & 2,46 & 0,88 & 0,93 & 0,69 & 0,75 & 0,79 & 0,78 & 0,65 & 0,73 \\
\hline$\beta$-Cadeneno & 1524 & 0,20 & 0,12 & 0,09 & 0,09 & 0,09 & 0,10 & 0,07 & 0,08 & 0,16 \\
\hline Espatulenol & 1576 & 0,54 & 0,14 & 0,10 & 0,07 & 0,06 & 0,05 & 0,07 & 0,04 & 0,14 \\
\hline Óxido cariofileno & 1581 & 0,12 & - & - & - & - & - & - & - & - \\
\hline
\end{tabular}

* Índice de retenção calculado por meio da série $n$-alcano em coluna capilar DB-5MS na ordem de eluição.

Fundação de Amparo à Pesquisa do Estado de Minas Gerais (FAPEMIG), pelo apoio financeiro.

\section{REFERÊNCIAS}

ADAMS, R.P. Identification of essential oil components by gas chromatography and mass spectroscopy. Illinois: Allured, 1995. 245p.

ARNON, D.I. Cooper enzymes in isolated chloplasts. Polyphenoloxidase in Beta vulgaris. Plant Physiology, v.24, n.1, p.1-15, 1949.

BENINCASA, M.M.P. Análise de crescimento de plantas. Jaboticabal: FUNEP, 2003. 41p.

BEZERRA, A.M.E. et al. Rendimento de biomassa, óleo essencial, teores de fósforo e potássio de chambá em resposta à adubação orgânica e mineral. Revista Ciência Agronômica, v.37, n.2, p.124-129, 2006.

BLANK, A.F. et al. Influência da adubação orgânica e mineral no cultivo de manjericão cv. Genovese. Revista Ciência Agronômica, v.36, n.2, p.175-180, 2005.

CORRÊA JÚNIOR, C. Influência das adubações orgânica e química na produção de camomila (Chamomilla recutita $\mathrm{L}$.
Rauschert) e do seu óleo essencial. In: MING, L.C. et al. Plantas medicinais, aromáticas e condimentares: avanços na pesquisa agronômica. Botucatu: UNESP, 1998. V.1, p.130164.

MAIA, S.S.S. Propagação, adubação orgânica e níveis de radiação nas características anatômicas e composição de óleo essencial em Hyptis suaveolens (L.) Poit. (Lamiaceae). 2006. 105f. Tese (Doutorado em Agronomia/ Fitotecnia) - Curso de Pós-graduação em Agronomia, Universidade Federal de Lavras.

MAPELI, N.C. et al. Produção de biomassa e de óleo essencial dos capítulos florais da camomila em função de nitrogênio e fósforo. Horticultura Brasileira, Brasília, v.23, n.1, p.32$37,2005$.

MARTINS, E.R. et al. Essential oil in the taxonomy of Ocimum selloi Benth. Journal Brazilian Chemmical Society, São Paulo, v.8, p.29-32, 1997.

MING, L.C. Adubação orgânica no cultivo de Lippia Alba (Mill.) N.E.Br. - Verbenaceae. In: MING, L.C. et al. Plantas medicinais, aromáticas e condimentares: avanços na pesquisa agronômica. Botucatu: UNESP, 1998. V.1, p.165-192.

NIST Mass Spec Data Center, S.E. Stein, director, 'Rention Indices' in NIST Chemistry Web Book, NIST Standard 
Reference Database Number 69. LINSTROM, P.J.; MALLARD, W.G. (Eds.). Jne2005, National Institute of Standards and Technology, Gaithersburg MF, 20899. Acesso em 24 de agosto de 2007. On line. Disponível em: (http:// nebook.nist.goo).

SCHEFFER, M.C. Influência da adubação orgânica sobre a biomassa, o rendimento e a composição do óleo essencial de Achillea millefolium L.- mil-folhas. In: MING, L.C. et al. Plantas medicinais, aromáticas e condimentares: avanços na pesquisa agronômica. Botucatu: UNESP, 1998. V.1, p.1-22.
SILVA, F.G. et al. Influence of manure and fertilizer on Baccharis trimera (Less) D.C. growth and essential oil yield. Journal of herbs Spices \& Medicinal Plants, v.12, n.1/2, p.1-11, 2006.

VAN DEN DOOL, H.; KRATZ, P.D. A generalization of the retention index system including linear temperature programmed gasliquid partition chromatography.

Journal 